Journal of Social Science 1 (2): 92-98, 2005

ISSN 1549-3652

(C) 2005 Science Publications

\title{
Preparedness for the Introduction of E-learning in Higher Education-The Case of Oman
}

\author{
${ }^{1}$ Z. A. Al-Khanjari, ${ }^{1}$ N. S. Kutti and ${ }^{2}$ A. S. S. Dorvlo \\ ${ }^{1}$ Department of Computer Science, ${ }^{2}$ Department of Mathematics and Statistics \\ College of Science, Sultan Qaboos University, P.O. Box 36, Al-Khodh 123, Sultanate of Oman
}

\begin{abstract}
The use of Web-based instruction (WBI) and with the availability of well-structured Course Management Tools there seems to be a prospectus of improving both the classroom and distance educations using e-Learning principle ${ }^{[1,2]}$. As the instructor community plays a central role in all education processes we are motivated to study the level of their cooperation with respect to applying WBI through Course Management Systems (WBI-CMS) to current education. Particularly, instructor awareness of the use of the Internet in the current education and secondly their vision towards augmenting current education using WBI-CMS are vital factors in the augment process. This study presents the results of a survey conducted across the academic community of the Science Faculty in Sultan Qaboos University (SQU), Sultanate of Oman. Survey outcome positively indicates that the overall instructor community with the science background is aware of the importance of computers in both their personal and professional use. Majority of science instructors have positively shown their mandate for the use of computers in facilitating the educational process, a proof for the basic hypothesis in this research.
\end{abstract}

Key words: Web-based instruction, information society, internet technology, distance education, course management system, webCT

\section{INTRODUCTION}

Internet Technology has effectively initiated a soft revolution in the current teaching-based education system $^{[3]}$. Particularly introduction of Web-Based Instruction tools to distance education ${ }^{[4]}$ and the exploitation of portals in industrial training ${ }^{[5]}$ have motivated researchers to investigate the feasibility of adopting WBI-CMS as a standard feature of future education. In general, the researchers believe that this could induce a transformation of the traditional teaching-based education into a new e-Learning-based education. In fact, individual instructors, driven by selfmotivation, are enhancing their courses electronically using email communication and web technology. At the same time course management portals such as WebCT $^{[6,7,8]}$ and Blackboard ${ }^{[9]}$ have been used on experimental basis towards improving the services of traditional education. Overall the use of Web Technology to deploy online mode of on-campus education is increasing ${ }^{[10,11]}$. Factors such as efficiency, globalisation, availability of interactive multimedia facilities and low-cost implementation may force the transformation of traditional classroom education into a fully Web-based on-line learning (i.e. e-Learning). The ultimate aim is to derive a standard and effective e-Learning scheme to achieve more efficient results than currently derived from the traditional education. It is worth noting that a wide use of CMS has prompted the international community to the development of open standards for on-line course management systems ${ }^{[12]}$. The success of WBI-CMS will however depend upon the co-ordinated effort by the three participating communities in education, i.e. management, instructors and students.

The management provides necessary infrastructure and creates the enabling environment for course development and deployment towards e-Learning perspective. Students, as consumers, would appreciate any improvements in the learning scheme as long as the new scheme offers better training and possibly more opportunity in the job market. Instructors on the other hand are the main drivers of traditional education and play a central role in designing and managing courses. Currently WBI is adapted very fast in the existing education $^{[13]}$. With the fast growing WBI-CMS the instructor role extends further as facilitator ${ }^{[14]}$. The changing instructional environment raises some fundamental issues. (1) Will the instructors be able to cope with their new role without any professional training? (2) As the new role expects the instructors to be familiar with the WBI technology in addition to their own academic duties, will they be given any reward? The second issue is not the focus of this study and our research here aims to investigate several problems facing the instructor community in the instructional evolution. The preparation of instructor community to participate in WBI-CMS requires answers to several

Corresponding Author: Z.A. Al-Khanjari, Department of Computer Science, College of Science, Sultan Qaboos University, P.O. Box 36, Al-Khodh 123, Sultanate of Oman 
questions. (1) Do the instructors like any change in the current education? (2) Do they have sufficient technical background to adopt the Internet in the current education? (3) Do they appreciate the services provided by the Internet? (4) Do they visualize any improvement in student performance by using Internet services in the current education? (5) Will they be able to augment their WBI-CMS courses with the required software support tools? (6) Will they be able to facilitate courses in all pedagogical aspects? (7) Will they maintain their effort in motivating students' independent learning? (8) Will they be able to monitor student performance continually? Obviously an investigation of instructors' background, motivation and vision on future education will be useful particularly in preparing them towards a new challenging e-Learning paradigm. This research investigates about how prepared instructors are and their vision towards WBI-based education in SQU. The results presented in this study are used to draw suitable training schemes for staff development.

Advantages and disadvantages of the formal education: Formal education is traditionally conducted in a classroom setting with instructors face-to-face with students. Over the years well-structured paradigms have evolved to improve and promote traditional classroom education. There are strategies aimed at general improvements in curricular, teaching resources, initial and in-service teacher training and increasing the time dedicated to learning and teaching. Also there are strategies aimed at improving quality and techniques for accessing and measuring quality of education ${ }^{[15]}$.

Overall, the established strategies have achieved some success in improving education. However, the traditional approach has several drawbacks. It is expensive, discriminatory, synchronous, rigid, centralized and businesslike among others. These factors may indirectly cause several industrial and social problems. Moreover, traditional education does not have the infrastructure to support distance education. This may result in discriminatory practices because only a few elite will have access to education. It is also difficult to intensify traditional education by introducing new skill-based education within a short time ${ }^{[16]}$. Moreover, any expansion of the traditional system is a costly affair ${ }^{[3]}$.

Internet technology and instructors literacy: Internet technology has been going through a revolution due to innovative features such as WWW and Multimedia Communications. The WWW represents data/ knowledge sources and Internet is used to carry them in Multimedia form. Effectively the Internet Technology has actually created an information society. Ultimately its use can be extended to support e-based domains (e.g. e-Commerce, e-Entertainment, e-Encyclopaedia and e-Education).
The level of e-Education in an institution depends, to a large extent, upon the Internet literacy of individual instructors. In the primitive phase, instructors can use the email/chat facility to augment their communication with students. In the medium phase instructors can use web pages to deliver in online the course-related information. In an advanced phase instructors may implement most of the pedagogical components of education in online using CMS tools. In a very advanced phase e-Education may use an interactive online learning environment using multimedia tools along with course management tools. In this phase instructors may enrich the delivery of course information with more functionalities such as virtual library and web mining. In conclusion, as the level of eEducation advances the instructor role will ultimately become the role of a course facilitator. This implies strongly that instructor literacy should improve not only in understanding the concepts of Internet-Based Services but also in applying them to evolve an effective online education.

As the instructors have been tightly coupled with the traditional education for a long time, one cannot expect them to acquire Internet literacy for the purpose of immediate implementation of any Internet-based Instruction (i.e. WBI-CMS). A proper training scheme should improve instructor literacy in an effective manner. It is vital to explore several facts around their experience with the current education as well as their exposure to Internet Technology before devising a suitable training scheme. Several questions such as the following may bring useful information around instructor role in education. Do instructors realize the usefulness of pedagogical aspects of current education? Do they recognize drawbacks of current education? Do they express reasons for those drawbacks? Have they been exposed to Internet technology? What are the Internet Services used by them? Do they tend to apply those Internet Services in the current education? Do they have tendency to use Internet Services in their own learning? Are there any variations across the Internet Literacy of instructors? Do they care about student learning? Can they incorporate student feedback effectively? If not, what limitations they are facing in the current education process? Finally do they have lack of motivation induced by misconception of their competency and vision?

A future mission of our education systems should be to prepare to face the needs of the growing information society ${ }^{[17]}$. Hence, conducting a thorough investigation over the needs of the instructor community and then addressing the same would lead to a meaningful approach to improving the traditional education. A carefully designed survey is an effective tool to investigate instructor community. If the ultimate aim is to improve current education using WBI, then the survey would reveal instructors' Internet literacy and 
their motivation. These results may be useful to address their problems ultimately.

\section{MATERIALS AND METHODS}

In order to understand the instructor vision on the current education as well as any influence on their vision due to the Internet a survey was conducted using a questionnaire format. After designing, pre-testing and reliability testing, the questionnaire was selfadministered to all the instructors of the college of science, Sultan Qaboos University, Oman. Part A of the questionnaire requested general information about the instructors. This included instructor status, gender, teaching experience and discipline. Part $\mathrm{B}$ was concerned with the usage of computers for either personal purposes or course development. Part C covered the use of resources and Part D was concerned with pedagogical aspects such as course content, assessment methods, tutorial, self-test, etc. Information on students' ability to meet the requirements of the learning process from the instructors' point of view was obtained in Part E. A copy of the questionnaire is in Appendix-A.

\section{RESULTS}

The collected data were transferred into the statistical package, SPSS for analysis ${ }^{[18]}$. The list of variables for the SPSS analysis along with their descriptions is shown in Appendix B. Since all the variables are categorical, one-way and two-way frequency tables were prepared. Chi-square tests were conducted to test for independence of the attributes ${ }^{[19]}$.

There were 86 respondents from the academic staff strength of 139 in the college of science. This gave a high response rate of $62 \%$. The department of Mathematics and Statistics was the largest department with $36 \%$ of the respondents. The Department of Biology had the lowest percentage of respondents, $7 \%$. This might indicate unpopularity of Internet among natural science instructors. This type of instructors needs motivation and training to improve their out look. There were 70 respondents (i.e. 82\%) at the Assistant Professor or higher level. Only 10 out of the 86 respondents (i.e. 12\%) were female. Sixty-two percent of academic staff had ten or more years of teaching and research experience while only $19 \%$ had less than 5 years of teaching-research experience.

Part B: Instructors' use of computers: Personal or course usage: Part B questions aim to identify the level of instructor competency in using computer technology. Table 1 shows the results obtained for the variables related to Part B of the questionnaire. The results indicate that the level of instructor recognition of both computer and Internet technology is high. Seventy one percent (i.e. 61 out of 86 respondents) used their computers on a daily basis for writing reports, letters and/or general documents. Seventy one percent (i.e. 61 out of 86 respondents) accessed their emails on a daily basis mainly for personal communications and communications associated with teaching duties. Almost 13\% (i.e. 12 out of 86 respondents) did not use emails at all. Sixty-four percent (i.e. 55 out of 86 instructors) devoted their computers solely for work related activities and therefore did not play any games on their computers. Only 5\% of academic staff (i.e. 4 out of 86 respondents) played computer games everyday on their computers. It was observed that $58 \%$ (i.e. 50 out of 86 respondents) surfed over the Internet daily and $29 \%$ (i.e. 25 out of 86 respondents) surfed over the Internet weekly looking for materials for personal information. The survey data also showed that $75 \%$ (i.e. 64 out of 86 respondents) surfed over the Internet at least once a week looking for course related information.

The majority of academic staff was familiar with the use of Internet technology at the level of email communication and document preparation. These two aspects of Internet literacy are essential to technology in education. Particularly, the email literacy will help faculty to understand the function of the internal communication between instructor and student supported by CMS. Similarly the experience with document preparation would help faculty in developing course-related documents within CMS. Also the results indicate that the majority of academic staffs were familiar with the World Wide Web (WWW) concept and were realizing the scope of WWW as a valuable online information source. The response gave a strong indication that the majority of academic staff was using Internet as an effective source of course-related information. The results indicated that faculty have the Internet surfing literacy that will help them to understand the structure of CMS without any formal training. Moreover this aspect of literacy will motivate them to use WWW resources for course development. The majority of faculty do not need any formal training for basic literacy on Internet Services. The faculty can easily map out functional structure of the CMS through a workshop. On the other hand a minority of faculty need a short course on Internet applications and hands on training to bring up their literacy level.

Part C: Resources aspects: Part of Table 1 showed the results obtained for some of the variables related to Part $\mathrm{C}$ of the questionnaire. Most of the academic staff (i.e. $94 \%$ or 81 out of 86 respondents) indicated that they visited the library at least once a month. Over $87 \%$ respondents (i.e. 73 out of 84) downloaded research papers at least once a month from the Internet. Fifteen percent (i.e. 12 out of 84 respondents) read research papers on a daily basis and 
Table 1: Results of Part B and C of the questionnaire

\begin{tabular}{|c|c|c|c|c|c|}
\hline & Daily & Weekly & Monthly & Not at all & Total \\
\hline $\begin{array}{l}\text { Personal Usage -Entertainment(Games, Movies, etc) } \\
\text { (a) }\end{array}$ & $4(4.8 \%)$ & $8(9.6 \%)$ & $16(19.3 \%)$ & $55(66.3 \%)$ & $83(100.0 \%)$ \\
\hline Personal Usage -Documentation (Writing Reports, etc) & $61(70.9 \%)$ & $17(19.8 \%)$ & $7(8.1 \%)$ & $1(1.2 \%)$ & $86(100 \%)$ \\
\hline Personal Usage -internet access communication (e-mail, chat, etc) & $81(94.2 \%)$ & $4(4.7 \%)$ & $0(0 \%)$ & $1(1.2 \%)$ & $86(100 \%)$ \\
\hline Personal Usage-internet access,information retrieval (www-surfing) & $50(58.8 \%)$ & $25(29.4 \%)$ & $9(10.6 \%)$ & $1(1.2 \%)$ & $85(100 \%)$ \\
\hline Course usage (Professional)- Developing application programs course materials & $33(38.8 \%)$ & $24(28.2 \%)$ & $12(14.1 \%)$ & $16(18.8 \%)$ & $85(100 \%)$ \\
\hline Course usage (documentation)- Writing reports preparing lectures etc) & $44(51.8 \%)$ & $29(34.1 \%)$ & $8(9.4 \%)$ & $4(4.7 \%)$ & $85(100 \%)$ \\
\hline Course usage (internet access)- communications (e-mails, chat, etc) & $61(72.6 \%)$ & $9(10.7 \%)$ & $3(3.6 \%)$ & $11(13.1 \%)$ & $84(100 \%)$ \\
\hline Course usage (internet access)- information retrieval (www-surfing) & $39(45.9 \%)$ & $25(29.4 \%)$ & $13(15.3 \%)$ & $8(9.4 \%)$ & $85(100 \%)$ \\
\hline Resources Aspects- visiting Library & $1(1.2 \%)$ & $28(32.6 \%)$ & $52(60.5 \%)$ & $5(5.8 \%)$ & $86(100 \%)$ \\
\hline Resources Aspects - downloading research paper from internet & $6(7.1 \%)$ & $28(33.3 \%)$ & $39(46.4 \%)$ & $11(13.1 \%)$ & $84(100 \%)$ \\
\hline Resources Aspects- reading research papers & $12(14.3 \%)$ & $43(51.2 \%)$ & $26(31.0 \%)$ & $3(3.6 \%)$ & $84(100 \%)$ \\
\hline
\end{tabular}

Table 2: Results of variables related to Part-D of the questionnaire

\begin{tabular}{|c|c|c|c|c|c|c|}
\hline Variable & $\begin{array}{l}\text { Strongly } \\
\text { Disagree }\end{array}$ & Disagree & Neutral & Agree & $\begin{array}{l}\text { Strongly } \\
\text { Agree }\end{array}$ & Total \\
\hline Is it useful to provide course outline? & $4(4.7 \%)$ & $0(0.0 \%)$ & $1(1.2 \%)$ & $9(10.5 \%)$ & $72(83.7 \%)$ & $86(100 \%)$ \\
\hline Is it useful to provide prescribed text books? & $4(4.7 \%)$ & $0(0.0)$ & $8(9.3 \%)$ & $15(17.4 \%)$ & $59(68.6 \%)$ & $86(100 \%)$ \\
\hline Is it useful to provide supporting reference text books? & $2(2.4 \%)$ & $6(7.1 \%)$ & $12(14.3 \%)$ & $42(50.0 \%)$ & $22(26.2 \%)$ & $84(100 \%)$ \\
\hline Is it useful to provide lecture notes? & $5(5.8 \%)$ & $13(15.1 \%)$ & $28(32.6 \%)$ & $24(27.9 \%)$ & $16(18.6 \%)$ & $86(100 \%)$ \\
\hline Is it useful to provide reading guidelines? & $2(2.4 \%)$ & $9(10.7 \%)$ & $28(33.3 \%)$ & $30(35.7 \%)$ & $15(17.9 \%)$ & $84(100 \%)$ \\
\hline Is it useful to provide regular tutorials? & $1(1.2 \%)$ & $7(8.1 \%)$ & $16(18.6 \%)$ & $31(36.0 \%)$ & $31(36.0 \%)$ & $86(100 \%)$ \\
\hline Is it useful to provide assignments? & $1(1.2 \%)$ & $4(4.7 \%)$ & $7(8.1 \%)$ & $36(41.9 \%)$ & $38(44.2 \%)$ & $86(100 \%)$ \\
\hline Is it useful to provide projects? & $2(2.4 \%)$ & $3(3.6 \%)$ & $16(19.0 \%)$ & $38(45.2 \%)$ & $25(29.8 \%)$ & $84(100 \%)$ \\
\hline Is it useful to provide project based on team work? & $5(5.9 \%)$ & $8(9.4 \%)$ & $25(29.4 \%)$ & $29(34.1 \%)$ & $18(21.2 \%)$ & $85(100 \%)$ \\
\hline Is it useful to provide self tests? & $5(6.0 \%)$ & $6(7.1 \%)$ & $30(35.7 \%)$ & $33(39.3 \%)$ & $10(11.9 \%)$ & $84(100 \%)$ \\
\hline Is it useful to provide quizzes? & $4(4.7 \%)$ & $1(1.2 \%)$ & $8(9.3 \%)$ & $38(44$ & $35(40.7 \%)$ & $86(100 \%)$ \\
\hline Is it useful to provide midterm exams? & $4(4.7 \%)$ & $2(2.3 \%)$ & $4(4.7 \%)$ & $20(23.3 \%)$ & $56(65.1 \%)$ & $86(100 \%)$ \\
\hline Is it useful to provide communicate with students & $4(4.7 \%)$ & $0(0.0 \%)$ & $2(2.4 \%)$ & $18(21.2 \%)$ & $61(71.8 \%)$ & $85(100 \%)$ \\
\hline Is it useful to provide personal communication with students? & $4(4.8 \%)$ & $2(2.4 \%)$ & $13(15.7 \%)$ & $21(25.3 \%)$ & $43(51.8 \%)$ & $83(100 \%)$ \\
\hline $\begin{array}{l}\text { Is it useful to provide feedback directly to students about } \\
\text { their performance? } \\
\text { Is it useful to implement some of the above aspects using }\end{array}$ & \%) & 3 & 5 & $\%)$ & $.3 \%)$ & $86(100 \%)$ \\
\hline Computers? & $5(5.9 \%)$ & $2(2.4 \%)$ & $16(18.8 \%)$ & $24(28.2 \%)$ & $38(44.7 \%)$ & $85(100 \%)$ \\
\hline
\end{tabular}

Table 3: Results of variables related to Part-E of the questionnaire

\begin{tabular}{llll}
\hline Variable & Yes & No & Total \\
\hline Lack of student's interest & $45(61.6 \%)$ & $28(38.4 \%)$ & $73(100 \%)$ \\
Difficult to motivate students & $38(55.1 \%)$ & $31(44.9 \%)$ & $69(100 \%)$ \\
Students prefer memorizing materials & $46(63.0 \%)$ & $27(37.0 \%)$ & $73(100 \%)$ \\
Student's inability/reluctance to participate in class discussions & $47(64.4 \%)$ & $26(35.6 \%)$ & $73(100 \%)$ \\
Student's inability/reluctance to do independent work & $53(72.6 \%)$ & $20(27.4 \%)$ & $73(100 \%)$ \\
Student's inability/reluctance to use material from prerequisite courses & $60(83.3 \%)$ & $12(16.7 \%)$ & $72(100 \%)$ \\
Students are reluctant to be challenged & $48(67.6 \%)$ & $23(32.4 \%)$ & $71(100 \%)$ \\
Lack of understanding English language & $46(63.9 \%)$ & $26(36.1 \%)$ & $72(100 \%)$ \\
Lack of understanding of course material & $33(47.8 \%)$ & $36(52.2 \%)$ & $69(100 \%)$ \\
\hline
\end{tabular}

$96 \%$ (i.e. 81 out of 84 respondents) read research papers on the Internet at least once a month without downloading. About $80 \%$ publish at least one research paper a year and about $70 \%$ attended conferences each year. In addition to teaching about $68 \%$ reported that they spent a few hours a week with students. Academic staff in the college is involved in research. For research support they use both the traditional library and Internet based facilities. The survey outcome shows that the majority of faculty are research-oriented and actively using the library as well as the Internet for their research. This aspect of literacy indicated the presence of instructor interest in the use of Internet in their research. With the same literacy the faculty can be motivated to understand the need for augmented CMS services for student e-Learning environment. The faculty will then be able to manage e-Learning based education without any further formal training. For the remaining faculty, a workshop on e-Learning in addition to workshop on CMS should be considered as necessary training.

Part D: Pedagogical apects: Table 2 showed the results obtained for the variables related to Part D of the questionnaire. There was a general agreement on most of the pedagogical aspects of teaching and instructional preferences. The majority of academic staff in the least agreed on the need for and usefulness of providing students with basic materials for learning. Almost all (i.e. $94 \%$ or 81 out of 86 respondents) strongly agreed that a course outline should be provided. Sixty-four percent (i.e. 59 out of 86 respondents) strongly agreed 
that prescribed textbooks should be used to support courses. Eighty six percent agreed on the usefulness of reference books. There were differences of opinion on the usefulness of providing lecture notes. Over $54 \%$ do not see the need for the provision of lecture notes. However 54\% agreed or strongly agreed that reading guidelines should be provided. On the whole the academic staff agreed on the need for regular tutorial, self-tests and project work. Most of the academic staff generally supported interim assessment of students. Sixty-five percent strongly supported mid-term examinations. A high proportion of instructors agreed on the need to provide general communications with students. However, only 52\% strongly agreed on providing personal communications to students and $60 \%$ strongly agreed on providing direct feedback on student performance. Seventy two percent (i.e. 62 out of the 86 respondents) agreed that computers should be provided to facilitate the educational process.

As almost every CMS comes with facilities to incorporate most of the pedagogical elements the instructors need some basic Internet literacy. According to the survey results most of the instructors seem to possess basic literacy that would help them in understanding CMS tools. A CMS workshop would be sufficient to help instructors design their online courses.

Part E: Instructor perception of students' attitude: Table 3 showed the results obtained for the variables related to Part $\mathrm{E}$ of the questionnaire. The staff responses showed a divided opinion on the lack of interest on the part of students as a factor that hindered student progress. Forty-five of staff expressed the opinion that there was an indication of the lack of interest among students in their work while 28 were of the opposite opinion. Indeed 55\% of the staff said that it was difficult to motivate students. Also students preferred to memorize materials rather than try to understand them. Fifty-three of the staffs agreed that the students were generally reluctant to do independent work and $68 \%$ affirmed that students do not like to be challenged. In the opinion of the majority of instructors students do not participate in class discussions. The majority of instructors agreed that this might be due to lack of the mastery of the English language, since the English language, which is not their mother tongue of the students, is the medium of instruction. The majority also agreed that the students were reluctant to use material from pre-requisite course(s).

Research outcomes: It is encouraging that instructors are accepting new technology and using it as a vital communication tool and source of information for their research. Instructors' familiarity with the Internet technology and their frequent use of it in mining the WWW indicate the recognition of the scope of the Internet technology. However the majority of instructors still use the library frequently for their research. The high use of the traditional library may be due to the non-availability of information (i.e. journals, books, reports, etc.) in electronic-form. As journals, books and reports become more and more available on the Internet instructors may tend to use them more and thereby use the traditional library less. This tendency is certainly unavoidable due to the scope and efficiency factors associated with on-line resources.

The results also indicate that the Internet was used as an extra source of course information in addition to textbooks and other study materials. The response seems to prove that the instructors appreciate the availability of on-line information and they also realize their additional responsibility for curriculum development and course implementation. This strongly indicates that instructors are taking the role of constructors and facilitators of courses. Instructors seem to be preparing themselves so as to be able to accommodate the new paradigm of education based on e-Learning. With the evidence of the growing use of online technology, the instructors with their traditional role as guides will eventually induce both graduate and research students to recognize Internet as a vital source of knowledge.

Instructors seemed to suggest that students would learn more effectively by maintaining an intensive testing environment. The instructor preference to have frequent student evaluations would obviously require more resources including more instructor time, extra tutors and markers. Instructors would be forced to look for other avenues, possibly e-Learning portals, if these resources were not provided. The availability of automatic testing facilities with portals may reduce the workload inherent in frequent testing.

In traditional education one-on-one communication with students is important. Instructors as prime-learners operated at a higher level than students. As teachers, instructors deliver lectures, supply reading materials and finally evaluate students' knowledge through homework, tests and examinations. Consequently students, under the traditional mode, see their responsibility reduced to memorizing materials suggested by their instructors. The students assume this role and avoid communicating with their instructors. Hence the motivation of students might be restricted because they might not be exposed to the wider scope of learning. The results of the survey indicated that traditional education does not motivate students to do independent work. As students are given prescribed textbooks along with a specified syllabus, their learning is explicitly defined within this boundary. Traditional education has no scope for developing self-learning skills ${ }^{[20]}$. Would students build confidence and selflearning skills when given the role of learning in addition to regular guidance by instructors? Would the communication skills of students improve when they 
develop self-learning skills or assume a learner's role? These questions need to be explored further.

Training schemes: The survey helps to classify instructors in the College of Science into four groups on the basis of their computer literacy in general. Group A is not familiar with the computers at all. Group B is familiar with the use of computers for email only. Group C is familiar with Internet services. Group D is familiar with Internet services as well as WBI. Accordingly we have suggested four training schemes (TS). TS1 covers the use of computers for emailing, reading news groups and basic web browsing including the usage of search engines. TS2 introduces various data formats and document preparing tools. TS3 covers multimedia documents. TS4 introduces WBI tools and e-Learning portals. Table 4 shows the training schemes that the different groups of instructors should undertake to enhance their use of e-Learning tools.

Table 4: Training Schemes for instructors

Instructor/Category Training scheme

\begin{tabular}{lllll} 
& TS1 & TS2 & TS3 & TS4 \\
\hline Group A & $\mathrm{X}$ & $\mathrm{X}$ & $\mathrm{X}$ & $\mathrm{X}$ \\
Group B & & $\mathrm{X}$ & $\mathrm{X}$ & $\mathrm{X}$ \\
Group C & & & $\mathrm{X}$ & $\mathrm{X}$ \\
Group D & & & & $\mathrm{X}$ \\
\hline
\end{tabular}

\section{CONCLUSION}

The results indicate a significant use of technology by instructors. A large of instructors used the Internet for course-related information. Instructors exploited the Internet technology for research and education. Hence, the introduction of a well-structured technology-based education model will not face any significant resistance from academic staff.

A few instructors did not use the Internet. We speculate that the non-use may be due to reluctance on their part to adopt new technology in their work. With adequate incentives these instructors may be encouraged to embrace the new technology. All instructors agreed that communications with students is important, but disagreed on the mode. Internet technology could be a fast and effective way of providing this communication. The instructor reaction in this survey indicates that a good alternative is the WBI-based classroom education with the use of an efficient course management system. These observations help the researchers to derive some structured training schemes for the instructors.

Based on our conclusion we have carried out training sessions involving series of seminars and workshops to integrate the use of currently available Course Management System (WebCT) with the existing classroom education in the College of Science. In a future study we shall evaluate the effect of the introduction of WebCT in the college of science and other colleges of Sultan Qaboos University.

\section{REFERENCES}

1. Khan, B.H., 1997. Web-Based Instruction (WBI): What is it and Why is it?, B.H. Khan (Ed), WebBased Instruction. Englewood Cliffs, NJ: Educational Technology Publications, pp: 5-19.

2. Daugherty, M. and B.L. Funke, 1998. University Faculty and Student Perceptions of Web-Based Instruction. J. Distance Edu., Vol. 13, Number 1, Retrieved from http://cade.atabascau.ca/vol13.1/augherty.tml, 2004.

3. Strehle, G.P., 2000. Distance Learning in America: How Institutions and Corporations are Stimulating Growth,http://www.ingenta.com/institute2000/strehle.pdf. Retrieved in 2004.

4. Lindner, J.R., 1999. Usage and Impact of the Internet for Appalachian chambers of commerce. J. Applied Commun., 83: 42-52.

5. Bray, J. Brockbank, Knowledge, the Universal, Differentiator,http://www.Expertmagazine.com/ articles/ knowledge.htm

6. LaBonte, R., S. Crichton and D. Allison, 2003. Moderating Tips for Synchronous Learning using Virtual Class Romm Technologies. Retrieved from http://www.odysseylearn.com/resource/emod.htm, 2004.

7. Goldberg, M.W. and S. Salari, 1997. An update on webCT (World-Wide-Web Course Tools) - a Tool for the Creation of Sophisticated Web-Based Learning Environments. Proc. of NAUWeb'97, June 12-15, 1997, Flagstaff, Arizona. Retrieved from http://star.ucc.nau.edu/ nauweb97/papers/goldberg/ goldberg.html, 2004.

8. WebCT Home Page, 2004. Retrieved from http://www.webct.com

9. Blackboard Learning System, 2004. Retrieved from http://www.blackboard.com/highered/academic/ls/i ndex. htm

10. Morgan, G., 2003. Faculty use of course management systems. Technical Report, EDUCAUSE Centre for Applied Research, May 2003. Retrieved from http:// www. educause.edu /ir/library/pdf /ecar_so/ers/ ers0302/ ekf0302.pdf

11. Shannon, S. and L. Doube, 2004. Valuing and using web supported teaching: A staff development role in closing the gaps. Australian J. Edu. Technol., 20: 114-136.

12. CETIS, 2004. Retrieved from http://www.cetis.ac.uk.

13. Crossman, D.M., 1997. The evolution of the World Wide Web as an emerging technology tool. In B.H. Kahn (Ed.), Web-based Instruction, Englewood Cliffs, NJ: Educational technology publications, pp: 19-25. 
14. Sorin Reesa, 2004. Webfolio: An online learning community to help link university studies and classroom practice in pre-service teacher education. Australian J. Edu. Technol., 20: 101-113.

15. Machado, A.L., 2000. Current status and perspectives for education in Latin America. Intl. Conf on the Bookmark of the School of the Future, Information and Communication Technologies in Education, The School of the Future, edited by Harriet Taylor and Pieter Hogenbirk, Kluwer Academic Publishers, pp: 1-20.

16. Issac, J.R., 2000. Identifying educational core competencies for the Information Age. IFIP TC3/WG3.1 Intl. Conf. on Information and Communication Technologies in Education, Vina del Mar, Chile, April, 2000, pp: 129-148.
17. Westbrock, J., 2000. The Esloo design for the digital elementary and secondary education. IFIP TC3/WG3.1 Intl. Conf. on Information and Communication Technologies in Education, Vina del Mar, Chile, April, 2000, pp: 55-70.

18. SPSS Inc., 2002. Statistical Package for the Social Sciences. Version 11.5. SPSS, Chicago, USA.

19. Agresti, A., 1996. An Introduction to Categorical Data Analysis. Wiley Series in Probability and Statistics, NY, USA.

20. Klaus-D.G. and Kiyoshi Yokochi, 2000. Students Teach students. IFIP TC3/WG3.1 Intl. Conf. on Information and Communication Technologies in Education, Vina del Mar, Chile, April, 2000, pp: 149-158. 